Discussion Paper No. 704

\title{
COLLUSION AND \\ RESEARCH JOINT VENTURES
}

\author{
Kaz Miyagiwa
}

December 2007

The Institute of Social and Economic Research Osaka University

6-1 Mihogaoka, Ibaraki, Osaka 567-0047, Japan 


\title{
Collusion and research joint ventures
}

\author{
Kaz Miyagiwa* \\ Emory University and Osaka University
}

Abstract: We examine whether cooperation in R\&D leads to product market collusion. Suppose that firms engage in a stochastic $R \& D$ race while maintaining the collusive equilibrium in a repeated-game framework. Innovation under competitive R\&D creates inter-firm asymmetries, which destabilizes the collusive equilibrium. Innovation sharing through cooperative R\&D preserves symmetries, thereby facilitating collusion. Sharing an efficient technology also increases industry profit, which contributes to the collusion stability but also raises social welfare. Interestingly, a welfare improvement is less likely if innovation leads to a large cost reduction. The effect of licensing under competition $\mathrm{R} \& \mathrm{D}$ is also examined.

JEL Classifications System Numbers: L12, L13

Keywords: Collusion, Research Joint Ventures, Innovation, $R \& D$

Correspondence: Kaz Miyagiwa, Institute of Social and Economic Research, Osaka University, 6-1 Mihogaoka, Ibaraki, Osaka 567-0047, JAPAN; E-mail: kmiyagiwa@gmail.com.

\footnotetext{
* I am grateful to an anonymous referee and especially Yeon-koo Che, Editor of This Journal, for their valuable comments and suggestions that led substantial improvements. Thanks also go to Sue Mialon and Yuka Ohno for their comments on earlier versions. Errors are my own responsibility.
} 


\section{Introduction}

This paper evaluates the age-old suspicion that cooperation in R\&D leads to product market collusion. Prior to the 1960s this suspicion was so strong in the U.S. that antitrust authorities threatened to punish any form of research joint ventures (RJVs) with full forces of antitrust laws. The sentiment abated during the 1960s and early 1970s, when key American industries were losing the competitive edge to foreign rivals that had made considerable technological progress through formation of RJVs. ${ }^{1}$ Although today joint $R \& D$ activities among firms are encouraged everywhere, the same old suspicion lingers: does cooperation in R\&D facilitate product market collusion? ${ }^{2}$

To investigate this question analytically, suppose that a group of ex ante symmetric firms manage implicitly to maintain a collusive equilibrium in an infinitely repeated-game framework. In such an environment, a firm that discovers a cost-cutting technology has a strong incentive to lower the price to increase its market share, thereby destabilizing the collusive arrangement. Further, the prospect that collusion breaks down with a discovery of new technology destabilizes collusion in pre-discovery periods.

Suppose that firms are allowed to form an RJV to share innovations. Cooperation in R\&D generates two effects that facilitate collusion. First, innovation sharing eliminates the inter-firm asymmetry, the source of collusion instability mentioned above. Second, innovation sharing gives all firms access to new technology and increases industry profit, the prospect of which contributes to the stability of collusion. ${ }^{3}$

\footnotetext{
${ }^{1}$ See Caloghirou, Ioannides and Vonortas (2003).

${ }^{2}$ For example, see the Federal Trade Commission's Comment and Hearings on Joint Venture Project to witness its continuing ambivalence towards RJVs (http//www.ftc.gov/os/1997/jointven.htm).

${ }^{3}$ I am grateful toYeon-koo Che for this insight.
} 
To separate these two effects, we consider the intermediate case in which firms license new technology without forming an RJV. Licensing allows industry to capture as much total surplus as it could as an RJV, but does not eliminate the asymmetry that exists between licensor and licensee. This asymmetry makes it more difficult for firms to maintain collusion relative to when they form an RVJ.

Welfare and policy implications of cooperative $R \& D$ are also considered. Although it facilitates collusion, an RJV also increases production efficiency, so social welfare need not fall. With licensing possibilities, however, an RJV never increases social welfare because industry productivity is already high with licensing.

These results are established in a model under the assumptions that innovation is non-drastic, the innovator has exclusive rights to the innovation for an indefinite period, and the collusive equilibrium is maintained with threats to Nash reversion. These assumptions are relaxed and the implications discussed later in the analysis.

There is a scanty literature on the relationship between cooperation in $R \& D$ and product market collusion. ${ }^{4}$ Martin (1995) uses a continuous-time version of a repeatedgame framework with stochastic innovation to show, as in this paper, that cooperative R\&D facilitates collusion. Contrary to our result, he finds that formation of RJVs reduces social welfare. The difference in welfare assessments lies with his assumption that collusion ends with a discovery. ${ }^{5}$ If innovation is non-drastic, collusion need not end with

\footnotetext{
${ }^{4}$ There is a huge literature on the relative effect of competitive and cooperative $R \& D$, most of which studies atemporal models, see, e.g., D'Aspremont and Jacquemin (1988), and Kamien, Muller and Zang (1992). An intertemporal model is developed in Miyagiwa and Ohno (2002).

${ }^{5}$ Cabral (2000) considers a similar model under the assumption that firms cannot observe each other's effort, and shows that firms may set the price below the monopoly price to sustain collusion under cooperative R\&D.
} 
a discovery of new technology, in which case welfare can be increased by formation of RJVs as we show below.

While Martin (1995) focuses exclusively on the stability of collusion before innovation, the stability of collusion after innovation takes center stage in the work of Lambertini, Poddar and Sasaki (2002, 2003). In the 2002 article, which more relates to the present paper, the authors consider a three-stage game, in which two firms first decide whether to form a joint venture, then choose horizontal locations in the Hotelling-style product space, and finally choose to compete or collude in prices over time. R\&D is deterministic, and corresponds to product location selection. In the second stage, firms can select a product location freely when acting competitively in R\&D but are constrained to choose a single location when acting as an RJV. When competitive in $\mathrm{R} \& \mathrm{D}$, collusive firms have no incentive to locate near the center of the product space, because that would only increase profits from a deviation without increasing the equilibrium profit. $^{6}$ Therefore, an RJV, which constrains firms to select an identical product location (at the center), makes collusion more difficult to maintain. Their model however offers no analysis of collusion in pre-discovery periods or the linkages between behaviors in pre-discovery and post-discovery periods. ${ }^{7}$

\footnotetext{
${ }^{6}$ Locating at the center, each firm covers half the interval, but the same result obtains if each firm locates at the midpoint between the center and the end point of the interval. However, in the latter case profit from a deviation is less due to product differentiation.

${ }^{7}$ Lambertini, Poddar and Sasaki (2003) develop a non-spatial model of product differentiation, where formation of an RJV is assumed and focus is on the firms' (costly) choice of product substitutability for the maintenance of collusion in post-discovery periods.
} 
A major difficulty that arises in the analysis of collusion in post-discovery periods is that there is no natural focal equilibrium due to cost asymmetries. ${ }^{8}$ There is a small but growing literature on collusion under cost heterogeneity, which typically assumes that firms maximize joint profits, and determines the unique equilibrium price and marketsharing rule by an appeal to the notion of balanced temptation equilibrium of Friedman $(1971)^{9}$. Bae (1987) initiates this approach in his analysis of Bertrand duopoly, while Verboven (1997), Rothschild (1999) and Collie (2004) examine Cournot cases. This approach however is not without criticism. Harrington (1991), for example, argues that the hypotheses of joint profits maximization and balanced temptation equilibrium are both ad hoc, and develops an alternative approach based on Nash bargaining.

However, the Harrington (1991) approach may also be subject to a subtler criticism that it does not model the negotiation process explicitly. If it takes long and hard negotiations to come to an agreement, such a process is likely to raise suspicion in the watchful eyes of antitrust authorities, thereby affecting the equilibrium outcome. Furthermore, when applied to the current situation, both the Nash bargaining and the joint-profit maximization approach turn out intractable because of ambiguous comparative-statics results with respect to cost changes. Therefore, in this paper we propose another approach, which may be called the price leadership hypothesis. Under this hypothesis, an innovator chooses a price and a market-share rule to maximizes his individual profit and makes a take-it-or-leave-it offer to the non-innovator. The price

\footnotetext{
${ }^{8}$ This difficulty is absent in Martin (1995) because collusion ends with a discovery in his model, and in Lambertini, Poddar and Sasaki (2002) because R\&D is non-stochastic and R\&D decisions are made simultaneously.
} 
leadership hypothesis is robust to the Harrington (1991) criticism and is more tractable than his or the joint-profit maximization approach.

The remainder of this paper is organized in six sections. In section 2 we give an overview of the model and discuss the non-cooperative equilibrium. Section 3 establishes the conditions for the collusive equilibrium under competitive R\&D. Section 4 is devoted to the analysis of firms' incentives to collude as an RJV. Section 5 examines the case in which firms can license new technology without forming an RJV. In Section 6, we extend the model to cases of drastic innovation, finite-period patent protection, and optimal punishment schemes. Section 7 concludes.

\section{Model}

\subsection{Setup}

We consider repeated interactions between two a priori symmetric firms over an infinite time horizon. Time is discrete and indexed by $t \geq 1$. At $t=1$ firms possess the common technology that enables them to produce homogeneous goods at the constant unit cost of $\bar{c}$. In any period $t \geq 1$, each firm decides whether to invest in $R \& D$ for the discovery of a new technology that will reduce the unit cost to $\underline{\mathrm{c}}(<\overline{\mathrm{c}})$. Investing in $\mathrm{R} \& \mathrm{D}$ requires a fixed cost $\mathrm{k}$ per period. ${ }^{10} \mathrm{R} \& \mathrm{D}$ investment is risky in the sense that it fails with probability $\phi<1$ per period. If both firms invest in R\&D, a discovery occurs to either

\footnotetext{
${ }^{9}$ This requires that the ratios of the per-period losses due to the breakdown of collusion over the maximum one-period gains from deviations be the same among firms.

${ }^{10}$ The assumption of fixed-intensity R\&D, adopted in Bloch and Markowitz (1996), Lambertini, Poddar and Sasaki (2002, 2003) and others, simplifies the analysis.
} 
firm with probability $2 \phi(1-\phi)$ and to both with probability $(1-\phi)^{2}$. In the case of simultaneous discoveries each firm has an equal chance of obtaining patent protection. ${ }^{11}$ Call a firm with the patent an innovator, and the other firm a non-innovator. Assume permanent patent protection for simplicity.

Firms are price-setters. Consumers buy from a firm offering a lower price. In case of ties, they buy from both firms equally so each firm captures half the market. Demand is stationary and is written $\mathrm{D}(\mathrm{p})$, where $\mathrm{p}$ is price. $\mathrm{D}(\mathrm{p})$ is differentiable, with first and second derivatives denoted by $\mathrm{D}^{\prime}(\mathrm{p})<0$ and $\mathrm{D}^{\prime \prime}(\mathrm{p}) \leq 0$. Let $\mathrm{p}^{\mathrm{m}}(\mathrm{c})$ be the unconstrained monopoly price when the unit cost is c, i.e., $\mathrm{p}^{\mathrm{m}}(\mathrm{c}) \equiv \operatorname{argmax} \mathrm{D}(\mathrm{p})(\mathrm{p}-\mathrm{c})$. The conditions on demand make industry profit strictly concave so $\mathrm{p}^{\mathrm{m}}$ (c) is unique. It is easy to check that $\mathrm{p}^{\mathrm{m}}(\underline{\mathrm{c}})<\mathrm{p}^{\mathrm{m}}(\overline{\mathrm{c}})$.

Lastly, if innovation is drastic, an innovator becomes a monopoly unthreatened by the non-innovator and hence has no incentive to collude in post-discovery periods. To study the linkages between pre-discovery and post-discovery behaviors, assume that innovation is non-drastic, i.e., $\overline{\mathrm{c}}<\mathrm{p}^{\mathrm{m}}(\underline{\mathrm{c}})$.

\subsection{Non-collusive equilibrium}

In the non-collusive game, each firm setting prices equal to $\overline{\mathrm{c}}$ in every period regardless of histories is a subgame-perfect Nash equilibrium (SPNE). Denote this

\footnotetext{
${ }^{11}$ This assumption is often adopted in the literature; see Cardon and Sasaki (1998), for example.
} 
strategy profile by $\lambda$. Adopting this strategy, firms earn zero profit (excluding the investment cost k) before a discovery. After a discovery the innovator limit-prices the non-innovator and earns the per-period profit of

$$
\pi_{\mathrm{L}}=\mathrm{D}(\overline{\mathrm{c}})(\overline{\mathrm{c}}-\underline{\mathrm{c}})>0
$$

while the non-innovator receives zero profits. ${ }^{12}$

Assuming that both firms invest in $R \& D$, with probability $\left(1-\phi^{2}\right) / 2$ each firm has the chance of obtaining the exclusive right to use the new technology and earning the perperiod profit $\pi_{\mathrm{L}}$. With probability $\phi^{2}$ investments flop for both firms, putting them in exactly the same state the next period as they are currently. This recursive structure of the model leads to the following equation:

$$
\mathrm{V}_{\lambda}=-\mathrm{k}+\delta\left(\pi_{\mathrm{L}} / 2\right)\left(1-\phi^{2}\right) /(1-\delta)+\delta \phi^{2} \mathrm{~V}_{\lambda}
$$

where $\mathrm{V}_{\lambda}$ denotes the present discounted sum of equilibrium profits, and $\delta(<1)$ denotes the common discount factor. Collecting terms,

$$
\mathrm{V}_{\lambda}=\frac{-k+\delta\left(1-\phi^{2}\right)\left(\pi_{L} / 2\right) /(1-\delta)}{1-\delta \phi^{2}}
$$

Assume $V_{\lambda}>0$ so investing in $R \& D$ is worthwhile for each firm.

\section{Collusion with non-cooperative $R \& D$}

\footnotetext{
${ }^{12}$ Strictly speaking, the innovator sets a price slightly below $\overline{\mathrm{c}}$ to capture the entire market.
} 
We now consider a class of trigger strategies with Nash threats that induce implicit collusion in pre-discovery and post-discovery periods. We begin with noncooperative $\mathrm{R} \& \mathrm{D}$.

\subsection{Collusion in post-discovery periods}

In post-discovery periods firms have asymmetric costs. As stated in section 1 we focus on the equilibrium based on the price leadership hypothesis, under which the innovator chooses a price and a market-share rule to maximize his profit and makes a take-it-or-leave-it offer to the non-innovator. ${ }^{13}$ Let $\left(\mathrm{p}^{\mathrm{c}}, \mathrm{s}\right)$ denote such an offer, where s $(0$ $<\mathrm{s}<1$ ) is the fraction of market served by the innovator.

The price leadership hypothesis amounts to the following. As soon as he has discovered new technology, the innovator communicates his optimal price and marketshare rule to the non-innovator and executes this decision in the first post-discovery period. If the non-innovator responds with the same price and the prescribed sales, then the collusion is on. Otherwise, the innovator believes that the non-innovator is uninterested in colluding, and starts behaving competitively. Formally, we consider the following strategy profile. Given that there is a discovery in period $\tau \geq 1$, in period $\tau+1$

firms set a price equal to $\mathrm{p}^{\mathrm{c}}$ and split the market according to the market-sharing rule $\mathrm{s}$. In $t \geq \tau+2$, they choose $\left(p^{c}, s\right)$ if no other outcomes than $\left(p^{c}, s\right)$ have been observed since $\tau$ +1 ; otherwise they adopt the non-collusive strategy $\lambda$ forever. Denote this strategy profile by a (a mnemonic for "after" a discovery). 
We look for the condition that makes a subgame-perfect in post-discovery games. If firms adopt a, every (post-discovery) subgame belongs to one of the two classes; one in which all past outcomes have been $\left(\mathrm{p}^{\mathrm{c}}, \mathrm{s}\right)$, and one in which another outcome has been observed at least in one post-discovery period. In the latter, $\lambda$ is subgame-perfect, so we need only to show that a is subgame-perfect in the first class of subgames.

Along this collusive equilibrium path, the innovator earns the per-period profit of

$$
\pi_{i}=s D\left(p^{c}\right)\left(p^{c}-\underline{c}\right)
$$

while the non-innovator earns

$$
\pi_{n}=(1-s) D\left(p^{c}\right)\left(p^{c}-\bar{c}\right)
$$

Since $\mathrm{p}^{\mathrm{c}}$ maximizes $\pi_{\mathrm{i}}$, put $\mathrm{p}^{\mathrm{c}}=\mathrm{p}^{\mathrm{m}}(\underline{\mathrm{c}})$. Then, we can write the above profits as

$$
\pi_{i}=s \underline{m}, \text { and } \pi_{n}=(1-s) D\left[p^{m}(\underline{c})\right]\left[p^{m}(\underline{c})-\bar{c}\right]
$$

where $\underline{m}$ denotes the monopoly profit under the new technology:

$$
\underline{\mathrm{m}} \equiv \mathrm{D}\left[\mathrm{p}^{\mathrm{m}}(\underline{\mathrm{c}})\right]\left[\mathrm{p}^{\mathrm{m}}(\underline{\mathrm{c}})-\underline{\mathrm{c}}\right]
$$

Let $v_{i}$ and $v_{n}$ denote the sums of equilibrium profits for the innovator and the noninnovator, respectively. The recursive structure implies

$$
v_{i}=\pi_{i}+\delta v_{i} \text {, and } v_{n}=\pi_{n}+\delta v_{n} \text {, }
$$

and hence:

\footnotetext{
${ }^{13}$ As explained in section 1 the main reason for this hypothesis is in its analytical tractability. By design, this scheme maximizes total profit for the innovator supported by Nash threats but is not optimal in the sense of Abreu (1986, 1988). The optimal collusion scheme is considered in section 6.
} 


$$
\mathrm{v}_{\mathrm{i}}=\pi_{\mathrm{i}} /(1-\delta) \text { and } \mathrm{v}_{\mathrm{n}}=\pi_{\mathrm{n}} /(1-\delta)
$$

Now consider a one-period deviation. A non-innovator can set the price slightly below $\mathrm{p}^{\mathrm{m}}(\underline{\mathrm{c}})$ to capture the entire market for the one-period profit of $\mathrm{D}\left[\mathrm{p}^{\mathrm{m}}(\underline{\mathrm{c}})\right]\left[\mathrm{p}^{\mathrm{m}}(\underline{\mathrm{c}})-\overline{\mathrm{c}}\right]$ but will lose all future profits when it gets limit-priced. He thus has no incentive to deviate if $\mathrm{v}_{\mathrm{n}} \geq \mathrm{D}\left[\mathrm{p}^{\mathrm{m}}(\underline{\mathrm{c}})\right]\left[\mathrm{p}^{\mathrm{m}}(\underline{\mathrm{c}})-\overline{\mathrm{c}}\right]$, which simplifies to

$$
\delta \geq s
$$

On the other hand, a deviating innovator can earn $\underline{m}$ one period and $\pi_{L}$ in all subsequent periods. Therefore, the innovator has no incentive to deviate if

$$
v_{i} \geq \underline{m}+\delta \pi_{L} /(1-\delta),
$$

or

$$
\delta \geq(1-\mathrm{s}) \underline{\mathrm{m}} /\left(\underline{\mathrm{m}}-\pi_{\mathrm{L}}\right)
$$

Thus, $\mathbf{a}$ is subgame-perfect in post-discovery games if

$$
\delta \geq \max \left\{(1-\mathrm{s}) \underline{\mathrm{m}} /\left(\underline{\mathrm{m}}-\pi_{\mathrm{L}}\right), \mathrm{s}\right\} .
$$

Now, the innovator chooses s to maximize sm subject to the non-innovator's incentive compatibility condition (2). This puts $s=\delta$. Substituting $s=\delta$ in (3) and rearranging yields

$$
\delta \geq \underline{\mathrm{m}} /\left(2 \underline{\mathrm{m}}-\pi_{\mathrm{L}}\right) \equiv \delta^{\mathrm{A}}(\underline{\mathrm{c}})>1 / 2 .
$$


The strategy profile $\mathbf{a}$ is a SPNE if (4) is satisfied. Observe that $\delta^{\mathrm{A}}(\underline{\mathrm{c}})>1 / 2$. Given the standard result that symmetric Bertrand firms can maintain collusion for $\delta \geq 0$, (4) indicates that a cost asymmetry makes collusion more difficult to maintain.

Define $c^{d}$ by $\bar{c}=p^{m}\left(c^{d}\right)$. Then $\underline{c}>c^{d}$ implies innovation is non-drastic. The next proposition summarizes what we have found so far.

Proposition 1: Assume non-drastic innovation $\left(\underline{c}>c^{d}\right)$.

(i) The strategy profile a is a SPNE for $\delta \geq \underline{\mathrm{m}} /\left(2 \underline{\mathrm{m}}-\pi_{\mathrm{L}}\right) \equiv \delta^{\mathrm{A}}(\underline{\mathrm{c}})>1 / 2$.

(ii) The collusive equilibrium price and market-sharing rule are

$$
\mathrm{p}^{\mathrm{c}}=\mathrm{p}^{\mathrm{m}}(\underline{\mathrm{c}}) \text { and } \mathrm{s}=\delta>1 / 2 \text {. }
$$

Since $s>1 / 2$, the innovator has a greater market share than the non-innovator, a result that is consistent with the findings of Bae (1987) and Harrington (1991). The per-period equilibrium profits are

$$
\pi_{i}=\delta \underline{m} \text { and } \pi_{n}=(1-\delta) D\left[p^{m}(\underline{c})\right]\left[p^{m}(\underline{c})-\bar{c}\right]
$$

Observe that the equilibrium profits to each firm are sensitive to the prevailing discount factor, whereas in Bae (1987) and Harrington (1991) they are independent of it as long as the discount factor exceeds the threshold level. 
The locus AA in Figure 1 plots $\delta^{\mathrm{A}}(\underline{\mathrm{c}})$ against $\underline{\mathrm{c}} .{ }^{14}$ The depiction reflects the fact that:

$$
\partial \delta^{\mathrm{A}}(\underline{\mathrm{c}}) / \partial \underline{\mathrm{c}}=\mathrm{D}(\overline{\mathrm{c}}) \mathrm{D}\left[\mathrm{p}^{\mathrm{m}}(\underline{\mathrm{c}})\right]\left[\overline{\mathrm{c}}-\mathrm{p}^{\mathrm{m}}(\underline{\mathrm{c}})\right] /\left(2 \underline{\mathrm{m}}-\pi_{\mathrm{L}}\right)^{2}<0
$$

for $\mathrm{p}^{\mathrm{m}}(\underline{\mathrm{c}})>\overline{\mathrm{c}}$ (i.e., non-drastic innovation). It is easy to check that $\delta^{\mathrm{A}}(\underline{\mathrm{c}})$ increases

towards unity as $\underline{\mathrm{c}}$ falls towards $\mathrm{c}^{\mathrm{d}}$ while in the other direction it approaches $1 / 2$ as $\underline{\mathrm{c}}$ approaches $\overline{\mathrm{c}}$. The intuition is straightforward. The greater a cost reduction, the more of an incentive to deviate the innovator has. To curb this incentive the threshold discount factor $\delta^{\mathrm{A}}(\underline{\mathrm{c}})$ must rise.

Proposition 1 says that if $\delta<\delta^{\mathrm{A}}(\underline{\mathrm{c}})$ firms cannot collude at the monopoly price $\mathrm{p}^{\mathrm{m}}(\underline{\mathrm{c}})$, but it leaves open the question whether they can collude at another price. However, such partial collusion is impossible as stated in the next lemma. Intuitively, because the market-sharing rule is sensitive to the discount factor in the present model, the innovator cannot commit credibly to his offer when the discount factor falls below the critical level $\delta^{\mathrm{A}}(\underline{\mathrm{c}})$. (The proof in Appendix A.)

Lemma 1. If $\delta<\delta^{\mathrm{A}}(\underline{\mathrm{c}})$, partial collusion is impossible in post-discovery subgames.

\footnotetext{
${ }^{14}$ We limit analysis to $\delta \geq 1 / 2$.
} 


\subsection{Collusion in pre-discovery periods}

We now turn to the stability of collusion in pre-discovery periods. Consider the

following symmetric strategy: In $t=1$, set a price equal to $\mathrm{p}^{\mathrm{m}}(\overline{\mathrm{c}})$, the monopoly price under the old technology. In any pre-discovery period $t \geq 2$, there are four possible states of nature.

(i) No other prices than $\mathrm{p}^{\mathrm{m}}(\overline{\mathrm{c}})$ have been observed and there was a discovery in $\mathrm{t}-1$.

(ii) No other prices than $\mathrm{p}^{\mathrm{m}}(\overline{\mathrm{c}})$ have been observed and there has been no discovery to date.

(iii) Prices other than $\mathrm{p}^{\mathrm{m}}(\overline{\mathrm{c}})$ have been observed at least once in the past and there was a discovery in $\mathrm{t}-1$.

(iv) Prices other than $\mathrm{p}^{\mathrm{m}}(\overline{\mathrm{c}})$ have been observed at least once in the past and there has been no discovery to date.

In state (i), adopt a. In state (ii) set the price equal to $\mathrm{p}^{\mathrm{m}}(\overline{\mathrm{c}})$. In states (iii) and (iv) adopt $\lambda$. Call this strategy profile $\mathbf{b}$ (a mnemonic for "before" a discovery).

Since $\mathbf{b}$ is subgame-perfect in states (i), (iii) and (iv), we need only to check state (ii). In state (ii) the equilibrium payoff, denoted by $\mathrm{V}_{\mathrm{c}}$, satisfies this recursive equation

$$
\mathrm{V}_{\mathrm{c}}=\overline{\mathrm{m}} / 2-\mathrm{k}+\delta\left(1-\phi^{2}\right)\left(\mathrm{v}_{\mathrm{i}}+\mathrm{v}_{\mathrm{n}}\right) / 2+\delta \phi^{2} \mathrm{~V}_{\mathrm{c}}
$$

where $\bar{m}$ denotes the monopoly profit under the old technology; i.e.,

$$
\overline{\mathrm{m}}=\mathrm{D}\left[\mathrm{p}^{\mathrm{m}}(\overline{\mathrm{c}})\right]\left[\mathrm{p}^{\mathrm{m}}(\overline{\mathrm{c}})-\overline{\mathrm{c}}\right)
$$


The right-hand side of (5) states that in every period before a discovery each firm earns half the monopoly profit $\bar{m}$ less the R\&D cost, and that each is equally likely to be the innovator or the non-innovator the next period, given probability of discovery $\left(1-\phi^{2}\right)$. Collecting terms in (5) yields

$$
\mathrm{V}_{\mathrm{c}}=\frac{\bar{m} / 2-\mathrm{k}+\delta\left(1-\phi^{2}\right)\left(\mathrm{v}_{\mathrm{i}}+\mathrm{v}_{\mathrm{n}}\right) / 2}{1-\delta \phi^{2}}
$$

Consider now a one-period deviation. By lowering the price infinitesimally below the monopoly price $\mathrm{p}^{\mathrm{m}}(\overline{\mathrm{c}})$, a deviating firm earns $(\overline{\mathrm{m}}-\mathrm{k})$ in the current period but finds itself in state (iii) or state (iv) the next period, with a switch to $\lambda$. Thus, the following is the expected profits from a deviation:

$$
\overline{\mathrm{m}}-\mathrm{k}+\delta\left(1-\phi^{2}\right)\left(\pi_{\mathrm{L}} / 2\right) /(1-\delta)+\delta \phi^{2} \mathrm{~V}_{\lambda}=\overline{\mathrm{m}}+\mathrm{V}_{\lambda}
$$

where the equality follows from (1). A deviation is unprofitable if this profit is less than $\mathrm{V}_{\mathrm{c}}$, i.e.,

$$
\mathrm{V}_{\mathrm{c}}-\mathrm{V}_{\lambda} \geq \overline{\mathrm{m}}
$$

where

$$
\mathrm{V}_{\mathrm{c}}-\mathrm{V}_{\lambda}=\frac{\delta\left(1-\phi^{2}\right)\left[\mathrm{v}_{\mathrm{i}}+\mathrm{v}_{\mathrm{n}}-\pi_{\mathrm{L}} /(1-\delta)\right] / 2+\overline{\mathrm{m}} / 2}{1-\delta \phi^{2}}
$$

The difference in profits, $\mathrm{V}_{\mathrm{c}}-\mathrm{V}_{\lambda}$, between the collusive and the competitive paths increases without bounds as $\delta$ goes to unity. Then, (6) holds with strict inequality for a high enough $\delta<1$. On the other hand, when $\delta$ is sufficiencly close to $1 / 2$, (6) fails, as 
shown in Appendix B. Therefore, there exists a unique $\delta \in(1 / 2,1)$ at which $(6)$ holds with strict equality. Denote this threshold discount factor by $\delta^{\mathrm{B}}(\underline{\mathrm{c}})$.

The locus BB (comprising the thick and dotted segments) in Figure 1 plots $\delta^{\mathrm{B}}(\underline{\mathrm{c}})$ against $\underline{\mathrm{c}}$, assuming that firms maintain the collusive equilibrium in post discovery periods and that $\phi^{2} \geq 1 / 2$. The depiction is based on the following lemma (see Appendix C for a proof):

Lemma 2: Given that $\mathrm{c}^{\mathrm{d}}<\underline{\mathrm{c}}<\overline{\mathrm{c}}$

(i) $\partial \delta^{\mathrm{B}}(\underline{\mathrm{c}}) / \partial \underline{\mathrm{c}}<0$

(ii) $1 / 2<\delta^{\mathrm{B}}(\underline{\mathrm{c}})<1 /\left(2 \phi^{2}\right)$.

(iii) If $\phi^{2} \geq 1 / 2$, there is a point ( $\left.\underline{\mathrm{c}}, \delta(\underline{\mathrm{c}})\right)$ at which the loci AA and BB intersect. ${ }^{15}$

Thus, the locus BB curves upward as $\underline{c}$ falls but stays strictly between $1 / 2$ and $1 /\left(2 \phi^{2}\right)$. If $\phi^{2}<1 / 2$, however, the upper bound exceeds unity, implying that the locus BB may stay above the locus AA for all $\underline{c}>c^{d}$.

\footnotetext{
${ }^{15}$ This establishes the existence. There may be more than one such point. However, the results we show below do not depend on the uniqueness.
} 
Finally, the analysis of this subsection is predicated on there being collusion in post-discovery periods, i.e., $\delta \geq \delta^{\mathrm{A}}(\underline{\mathrm{c}})$. Thus, we have

Proposition 2: If $\delta \geq \max \left\{\delta^{\mathrm{A}}(\underline{\mathrm{c}}), \delta^{\mathrm{B}}(\underline{\mathrm{c}})\right\}>1 / 2$, the strategy profile $\mathbf{b}$ is subgame-perfect and entails collusion in pre-discovery and post-discovery periods.

The prospect that a cost asymmetry can destabilize collusion in post-discovery periods makes collusion more difficult to maintain in pre-discovery periods, during which costs are symmetric. In Figure 1, collusion is sustainable before and after a discovery if the $(\delta, \underline{\mathrm{c}})$ pair is in region 1 defined by the set $\left\{(\delta, \underline{\mathrm{c}}) \mid \delta \geq \max \left\{\delta^{\mathrm{A}}(\underline{\mathrm{c}}), \delta^{\mathrm{B}}(\underline{\mathrm{c}})\right\}\right\}$. Outside region 1, the strategy profile $\mathbf{b}$ cannot support full collusion. In region 2 defined by the set $\left\{(\delta, \underline{\mathrm{c}}) \mid \delta^{\mathrm{A}}(\underline{\mathrm{c}}) \leq \delta<\delta^{\mathrm{B}}(\underline{\mathrm{c}})\right\}$, for example, firms can maintain collusion after a discovery but cannot before a discovery, because the monopoly price $\mathrm{p}^{\mathrm{m}}(\overline{\mathrm{c}})$ cannot satisfy the no-deviation condition (6). The question is: can firms collude partially, that is, at a price different from the monopoly price $\mathrm{p}^{\mathrm{m}}(\overline{\mathrm{c}})$ until there is a discovery? As in the post-discovery game, the next lemma shows they cannot (the proof in Appendix D).

Lemma 3. If $\delta^{\mathrm{A}}(\underline{\mathrm{c}}) \leq \delta<\delta^{\mathrm{B}}(\underline{\mathrm{c}})$ there is no partial collusion in pre-discovery periods. 
Thus, in region 2, although they cannot collude in pre-discovery periods, firms can fully collude in post-discovery periods by playing a competitive one-shot game until there is a discovery and then switch to playing a. This is a SPNE, yielding zero profits (minus investment cost $\mathrm{k}$ ) until a discovery and $\underline{\mathrm{m}} / 2$ per period afterwards.

Outside of regions 1 and 2, firms cannot collude partially after a discovery. Given that they play a limit-price game after a discovery, however, firms may still be able to collude up to a discovery by playing (the pre-discovery components of) b until a discovery and then switching to $\lambda$. Since firms adopting this strategy play the limitpricing game after a discovery, the first term in the numerator of (7) vanishes, and the condition to support collusion in pre-discovery period is given by

$$
(\overline{\mathrm{m}} / 2) /\left(1-\delta \phi^{2}\right)>\overline{\mathrm{m}},
$$

instead of by (6). This inequality holds if $\delta \geq 1 /\left(\not \phi^{2}\right)$. This condition is satisfied if the $(\delta, \underline{\mathrm{c}})$ pair is in region 3 of Figure 1 defined by $\left\{(\delta, \underline{\mathrm{c}}) \mid 1 /\left(2 \phi^{2}\right) \leq \delta<\delta^{\mathrm{A}}(\underline{\mathrm{c}})\right\}$, which is non-empty if $\phi$ is greater than $\sqrt{2} / 2$. Outside all these regions firms cannot collude at all.

\section{Research joint ventures}

We interpret the RJV broadly to encompass any technology-sharing arrangement including a royalty-free cross-licensing agreement, under which each firm runs its own research lab, incurs own $R \& D$ costs and gains free access to any innovations made by 
partners. We thus assume that each firm retains its R\&D facility and shares technology with each other, as is commonly assumed in the RVJ literature. ${ }^{16}$

\subsection{Collusion in post-discovery periods}

Suppose there is a discovery in period $\tau \geq 1$ and the firms adopt the following post-discovery strategy, denoted by $\boldsymbol{\alpha}$. In $\tau+1$, set a price equal to the monopoly price $\mathrm{p}^{\mathrm{m}}(\underline{\mathrm{c}})$ under the new technology. In all $\mathrm{t}+\tau,(\mathrm{t} \geq 2)$, choose $\mathrm{p}^{\mathrm{m}}(\underline{\mathrm{c}})$ if no other prices than $\mathrm{p}^{\mathrm{m}}(\underline{\mathrm{c}})$ have been observed since $\tau+1$; otherwise set a price to $\underline{\mathrm{c}}$. Thus, $\boldsymbol{\alpha}$ is a standard collusive strategy profile for symmetric price-setting duopoly and is a SPNE for $\delta \geq 1 / 2$. Compared with Proposition 1, this result shows that formation of an RJV facilitates collusion in post-discovery periods by preventing a cost asymmetry from arising. The question is how low the threshold discount factor falls in pre-discovery periods. We turn to this question next.

\subsection{Collusion in pre-discovery periods}

Consider the following collusive strategy denote by $\beta$ : In $t=1$, set a price equal to the monopoly price $\mathrm{p}^{\mathrm{m}}(\overline{\mathrm{c}})$ under the old technology. In any pre-discovery period $\mathrm{t} \geq 2$, there are four possible states of nature.

(i) No other prices than $\mathrm{p}^{\mathrm{m}}(\overline{\mathrm{c}})$ have been observed, and there was a discovery in $\mathrm{t}-1$.

(ii) No other prices than $\mathrm{p}^{\mathrm{m}}(\overline{\mathrm{c}})$ have been observed and there has been no discovery to date.

\footnotetext{
${ }^{16}$ See Kamien, Muller and Zang (1992) and Miyagiwa and Ohno (2002), for example.
} 
(iii) Prices other than $\mathrm{p}^{\mathrm{m}}(\overline{\mathrm{c}})$ have been observed at least in one period in the past and there was a discovery in $\mathrm{t}-1 .{ }^{17}$

(iv) Prices other than $p^{m}(\bar{c})$ have been observed at least once in the past and there has been no discovery to date.

In state (i) adopt $\boldsymbol{\alpha}$. In state (ii) set a price equal to $\mathrm{p}^{\mathrm{m}}(\overline{\mathrm{c}})$. In state (iii) set a price equal to $\underline{\mathrm{c}}$ in every period. In state (iv), withdraw from the RJV and switch to playing $\lambda$ forever.

The strategy profile $\beta$ is subgame-perfect in states (i), (iii) and (iv), so we only need to check state (ii). In that state, $V_{J}$, the equilibrium profit per firm, satisfies the following recursive equation:

$$
\mathrm{V}_{\mathrm{J}}=\overline{\mathrm{m}} / 2-\mathrm{k}+\delta\left(1-\phi^{2}\right)(\underline{\mathrm{m}} / 2) /(1-\delta)+\delta \phi^{2} \mathrm{~V}_{\mathrm{J}}
$$

which indicates that each firms earn half the monopoly profit $\overline{\mathrm{m}}$ less the R\&D cost before a discovery and also splits the post-discovery profit. Collecting terms, we obtain

$$
\mathrm{V}_{\mathrm{J}}=\frac{\bar{m} / 2-k+\delta\left(1-\phi^{2}\right)(\underline{m} / 2) /(1-\delta)}{1-\delta \phi^{2}}
$$

A one-period deviation before a discovery raises a deviating firm's profit to $\overline{\mathrm{m}}$ but puts firms in states (iii) or (iv) the next period, depending on whether there is a discovery during the period in question. In state (iii), which occurs with probability $\left(1-\phi^{2}\right)$, firms share the innovation but a switch to playing the one-shot symmetric Bertrand game

\footnotetext{
${ }^{17}$ Here, a subtle question arises: who owns the innovation when a deviation occurs. We assume that innovation is shared since it has occurred before breakup of the RJV.
} 
forever wipes out all future profits. In state (iv), which arises with probability $\phi^{2}$, firms switch to the non-collusive strategy $\lambda$, which has the prevent value of $\mathrm{V}_{\lambda}$. Thus, a deviation yields the profit of

$$
\overline{\mathrm{m}}-\mathrm{k}+\delta \phi^{2} \mathrm{v}_{\lambda}
$$

A firm therefore has no incentive to deviate if

$$
\mathrm{V}_{\mathrm{J}} \geq \overline{\mathrm{m}}-\mathrm{k}+\delta \phi^{2} \mathrm{~V}_{\lambda}
$$

After arranging terms, this condition can be rewritten

$$
\delta\left(1-\phi^{2}\right)(\underline{m} / 2) /(1-\delta)+\delta \phi^{2}\left(V_{J}-V_{\lambda}\right) \geq \bar{m} / 2
$$

where

$$
\mathrm{V}_{\mathrm{J}}-\mathrm{V}_{\lambda}=\frac{\delta\left(1-\phi^{2}\right)\left(\underline{\mathrm{m}} / 2-\pi_{\mathrm{L}} / 2\right) /(1-\delta)+\overline{\mathrm{m}} / 2}{1-\delta \phi^{2}}
$$

Differentiation shows that the left-hand side of (8) is increasing in $\delta$ for the same reason explicated in the case of non-cooperative R\&D. Further, we prove, in Appendix E, that (8) holds with strict inequality at $\delta=1 / 2$. Thus, (8) holds with strict inequality for all $\delta \geq 1 / 2$. Hence,

Proposition 3. The strategy $\beta$ is subgame perfect for $\delta \geq 1 / 2$

Thus, formation of an RJV lowers the threshold discount factors both in pre-discovery and in post-discovery periods to $1 / 2$ for all $\underline{\mathrm{c}}>\mathrm{c}^{\mathrm{d}}$. A comparison with the non- 
cooperative case, in which the threshold discount factor exceeds $1 / 2$, indicates that cooperative $R \& D$ leads to collusion everywhere outside region 1 . It is in this sense that formation of an RJV facilitates collusion.

Proposition 4. Formation of an RJV facilitates collusion for all $\underline{c}>c^{d}$ if

$$
1 / 2 \leq \delta<\max \left\{\delta^{\mathrm{A}}(\underline{\mathrm{c}}), \delta^{\mathrm{B}}(\underline{\mathrm{c}})\right\} .
$$

\subsection{Welfare implications}

Collusion reduces social welfare as firms set the monopoly price. However, it should not be inferred that cooperation in R\&D should be banned or penalized, for sharing of new can increase social welfare by making not just the innovator but both firms more efficient. The net welfare impact of cooperation in $R \& D$ thus depends on both these factors.

In region 1 of Figure 1, firms collude before and after a discovery without cooperation in R\&D. Therefore, formation of an RJV does not exacerbate the market distortions, and the technology-sharing effect raises welfare. In region 2, without cooperation in $\mathrm{R} \& \mathrm{D}$ firms manage to maintain collusion only after a discovery. Then, by the efficiency argument, welfare must rise with formation of an RJV in post-discovery periods. However, welfare falls in pre-discovery periods as firms collude as an RJV. The net welfare impact is in general ambiguous.

In region 3, without cooperation in $\mathrm{R} \& \mathrm{D}$ firms can collude only before a discovery. Thus, formation of an RJV generates no welfare change before a discovery. In 
post-discovery periods, firms collude only as an RJV. While monopoly pricing reduces welfare, technology sharing increases welfare. In this particular case, however, industry without an RJV is just as efficient as with an RJV, because due to limit-pricing only the innovator is active. Therefore, formation of an RJV results only in monopoly pricing, reducing welfare. ${ }^{18}$ To show this formally, let $\mathrm{p}(\mathrm{x})=\mathrm{D}^{-1}(\mathrm{p})$ be the inverse demand function. Then social welfare without formation of the RJV is given by

$$
\mathrm{W}^{\mathrm{C}}=\int_{0}^{D(\bar{c})} p(x) d x-D(\bar{c}) \bar{c}+D(\bar{c})(\bar{c}-\underline{c})
$$

where the first two terms on the right is consumer surplus and the third is industry profit. Similarly, social welfare with the RJV is written

$$
\mathrm{W}^{\mathrm{J}}=\int_{0}^{D\left[p^{m}(\underline{c})\right]} p(x) d x-D\left[p^{m}(\underline{c})\right] p^{m}(\underline{c})+D\left[p^{m}(\underline{c})\right]\left[p^{m}(\underline{c})-\underline{c}\right] .
$$

Taking the difference,

$$
\mathrm{W}^{\mathrm{J}}-\mathrm{W}^{\mathrm{C}}=-\int_{D\left[p^{m}(\underline{c})\right]}^{D(\bar{c})} p(x) d x+\left\{D(\underline{c})-D\left[p^{m}(\underline{c})\right]\right\} \underline{c} .
$$

Since $p(x)$ between the limits of integration is greater than $\underline{c}$, we have

$$
\int_{D\left[p^{m}(\underline{c})\right]}^{D(\bar{c})} p(x) d x>\int_{D\left[p^{m}(\underline{c})\right]}^{D(\bar{c})} \underline{c} d x=\left\{D(\underline{c})-D\left[p^{m}(\underline{c})\right]\right\} \underline{c} .
$$

Therefore, $\mathrm{W}^{\mathrm{J}}-\mathrm{W}^{\mathrm{C}}<0$; although having no welfare effect in the pre-discovery phase, formation of an RJV reduces post-discovery welfare. Similarly, welfare falls unambiguously outside the three regions.

\footnotetext{
18 As observed by Yeon-Koo Che, this is strictly due to price competition. If the non-innovator also
} 
To sum, an RJV increases welfare only by making the whole industry more efficient instead of just the innovator through innovation sharing. Although a large cost reduction can therefore result in a greater welfare improvement, with a large cost reduction we are likely to be in regions 3 and 4 initially, where formation of an RJV lowers welfare as we saw above. Thus we have a counterintuitive result: sharing a costcutting technology under $\mathrm{R} \& \mathrm{D}$ cooperation drives welfare improvements, but with a large cost reduction welfare is likely to fall with formation of an RJV. In contrast, with a small cost reduction, firms are likely to be collusive anyway, so formation of an RJV has only the beneficial technology-sharing effect. This observation has the obvious policy implication for antitrust authorities: firms should be more closely monitored for anticompetitive behavior when an RJV aims at a major technological breakthrough.

\section{Licensing without $\mathrm{RJVs}^{19}$}

In this section, we allow firms to license innovation without forming an RJV. As mentioned in section 1, formation of an RJV in preceding sections facilitates collusion through two effects. One is the asymmetry story. Innovation sharing eliminates inter-firm asymmetry, a source of instability. The other is the efficiency story; the prospect of a greater industry profit in post-discovery periods makes collusion easier to maintain in pre-discovery periods.

Licensing allows both firms to use innovation, thereby making industry as efficient as with an RJV. However, with licensing there remains an inter-firm asymmetry

produced, an RJV improves production efficiency so the welfare might increase.

${ }^{19}$ I thank Yeon-koo Che for his suggestion to explore this issue. 
in profit between the innovator (licensor) and the non-innovator (licensee). We show that this asymmetry makes collusion more difficult to maintain with licensing than with an RJV in pre-discovery periods but not in post-discovery periods.

The analysis of this section follows that of section 3. However, to save space we replicate only the relevant part from that section. With licensing, a rich taxonomy of cases may also arise, depending on the legal environments; for example, the durations of licensing and conditions for discontinuation or annulment of licenses. For simplicity, we suppose that a licensing agreement is good only for one period but extendable indefinitely as long as both parties agree to keep it.

Let a licensing contract be represented by a triplet $\{p, s, F\}$, where $p$ is a price, $s$ is a market share to the innovator and $\mathrm{F}$ is a licensing fee or transfer from the non-innovator to the innovator. Suppose that the innovator makes a take-it-or-leave-it offer to the noninnovator, and firms share innovation if the non-innovator accepts the offer. On the collusive equilibrium path with an licensing agreement, the non-innovator enjoys the profit $(1-\mathrm{s}) \mathrm{D}(\mathrm{p})(\mathrm{p}-\underline{\mathrm{c}})-\mathrm{F}$ and the non-innovator $\mathrm{sD}(\mathrm{p})(\mathrm{p}-\underline{\mathrm{c}})+\mathrm{F}$ per period.

We characterize the optimal contract in three steps. First, if the non-innovator refuses licensing, firms can still collude as in subsection 3.1, yielding to the noninnovator the equilibrium profit $(1-\delta) \mathrm{D}\left[\mathrm{p}^{\mathrm{m}}(\underline{\mathrm{c}})\right]\left[\mathrm{p}^{\mathrm{m}}(\underline{\mathrm{c}})-\overline{\mathrm{c}}\right]$ per period. The optimal licensing fee extracts any gain to the non-innovator; i.e., $\mathrm{F}$ is given by

$$
\mathrm{F}=(1-\mathrm{s}) \mathrm{D}(\mathrm{p})(\mathrm{p}-\underline{\mathrm{c}})-(1-\delta) \mathrm{D}\left[\mathrm{p}^{\mathrm{m}}(\underline{\mathrm{c}})\right]\left[\mathrm{p}^{\mathrm{m}}(\underline{\mathrm{c}})-\overline{\mathrm{c}}\right] .
$$

Using this, the profit to the innovator is written 


$$
\mathrm{D}(\mathrm{p})(\mathrm{p}-\underline{\mathrm{c}})-(1-\delta) \mathrm{D}\left[\mathrm{p}^{\mathrm{m}}(\underline{\mathrm{c}})\right]\left[\mathrm{p}^{\mathrm{m}}(\underline{\mathrm{c}})-\overline{\mathrm{c}}\right] .
$$

Since the second term is independent of $p$, the innovator sets $p=p^{m}(\underline{c})$ to maximize the above profit. With this pricing, the optimal licensing fee is written

$$
\mathrm{F}^{*}=(1-\mathrm{s}) \underline{\mathrm{m}}-(1-\delta) \mathrm{D}\left[\mathrm{p}^{\mathrm{m}}(\underline{\mathrm{c}})\right]\left[\mathrm{p}^{\mathrm{m}}(\underline{\mathrm{c}})-\overline{\mathrm{c}}\right] .
$$

Next, with the optimal price $\mathrm{p}^{\mathrm{m}}(\underline{\mathrm{c}})$, a one-period deviation allows the noninnovator to capture the entire market less the licensing fee for just one period, after which it gets limit-priced and loses all the future profits. Therefore, a deviation would yield

$$
\mathrm{D}\left[\mathrm{p}^{\mathrm{m}}(\underline{\mathrm{c}})\right]\left[\mathrm{p}^{\mathrm{m}}(\underline{\mathrm{c}})-\underline{\mathrm{c}}\right]-\mathrm{F}^{*}=\mathrm{s} \underline{\mathrm{m}}+(1-\delta) \mathrm{D}\left[\mathrm{p}^{\mathrm{m}}(\underline{\mathrm{c}})\right]\left[\mathrm{p}^{\mathrm{m}}(\underline{\mathrm{c}})-\overline{\mathrm{c}}\right] .
$$

On the other hand, since the optimal licensing fee $\mathrm{F}^{*}$ extracts any increase in profit, keeping his equilibrium profit per period at $(1-\delta) \mathrm{D}\left[\mathrm{p}^{\mathrm{m}}(\underline{\mathrm{c}})\right]\left[\mathrm{p}^{\mathrm{m}}(\underline{\mathrm{c}})-\overline{\mathrm{c}}\right]$ as in subsection 3.1. Thus, the non-innovator has no incentive to deviate if

$$
\mathrm{D}\left[\mathrm{p}^{\mathrm{m}}(\underline{\mathrm{c}})\right]\left[\mathrm{p}^{\mathrm{m}}(\underline{\mathrm{c}})-\overline{\mathrm{c}}\right] \geq \mathrm{sm}+(1-\delta) \mathrm{D}\left[\mathrm{p}^{\mathrm{m}}(\underline{\mathrm{c}})\right]\left[\mathrm{p}^{\mathrm{m}}(\underline{\mathrm{c}})-\overline{\mathrm{c}}\right] .
$$

This simplifies to

$$
\delta \mathrm{D}\left[\mathrm{p}^{\mathrm{m}}(\underline{\mathrm{c}})\right]\left[\mathrm{p}^{\mathrm{m}}(\underline{\mathrm{c}})-\overline{\mathrm{c}}\right] \geq \underline{\mathrm{m}} \text {. }
$$

The optimal market share must satisfy this constraint, and hence we have

$$
\mathrm{s}^{*}=\delta \mathrm{D}\left[\mathrm{p}^{\mathrm{m}}(\underline{\mathrm{c}})\right]\left[\mathrm{p}^{\mathrm{m}}(\underline{\mathrm{c}})-\overline{\mathrm{c}}\right] / \underline{\mathrm{m}} \text {. }
$$


Since the right-hand side expression of the above equation is less than $\delta$, a comparison with the counterpart in proposition 1 indicates that licensing results in a smaller market share for the innovator. In equilibrium, however, due to the licensing fee the innovator earns a greater net profit equaling:

$$
\mathrm{s}^{*} \underline{\mathrm{m}}+\mathrm{F}^{*}=\underline{\mathrm{m}}-(1-\delta) \mathrm{D}\left[\mathrm{p}^{\mathrm{m}}(\underline{\mathrm{c}})\right]\left[\mathrm{p}^{\mathrm{m}}(\underline{\mathrm{c}})-\overline{\mathrm{c}}\right] .
$$

Finally, the licensing agreement must be incentive-compatible for the innovator. A one-period deviation would yield $\underline{\mathrm{m}}+\mathrm{F}^{*}$ in the current period. As the innovator switches to limit-pricing in the next period, with the license annulled, the stream of discounted profits from the next period on sums to $\delta \pi_{L} /(1-\delta)$. Thus, a deviation yields

$$
\underline{\mathrm{m}}+\mathrm{F}^{*}+\delta \pi_{\mathrm{L}} /(1-\delta)=2 \underline{\mathrm{m}}-\mathrm{D}\left[\mathrm{p}^{\mathrm{m}}(\underline{\mathrm{c}})\right]\left[\mathrm{p}^{\mathrm{m}}(\underline{\mathrm{c}})-\overline{\mathrm{c}}\right]+\delta \pi_{\mathrm{L}} /(1-\delta)
$$

where (9) is used to get the right-hand side. The innovator has no incentive to deviate if this sum is less than the equilibrium profits; i.e.,

$$
\left(\mathrm{s}^{*} \underline{\mathrm{m}}+\mathrm{F}^{*}\right) /(1-\delta) \geq 2 \underline{\mathrm{m}}-\mathrm{D}\left[\mathrm{p}^{\mathrm{m}}(\underline{\mathrm{c}})\right]\left[\mathrm{p}^{\mathrm{m}}(\underline{\mathrm{c}})-\overline{\mathrm{c}}\right]+\delta \pi_{\mathrm{L}} /(1-\delta) .
$$

Substituting for $\mathrm{s}^{*}$ and $\mathrm{F}^{*}$ and canceling terms simplifies this to

$$
\delta \geq \underline{\mathrm{m}} /\left(2 \underline{\mathrm{m}}-\pi_{\mathrm{L}}\right) \equiv \delta^{\mathrm{A}}(\underline{\mathrm{c}}),
$$

the condition identical to (4) in section 3.1. Thus, the condition for collusion in postdiscovery periods is unaffected by licensing. It follows that a greater industry profit due to cooperation in R\&D has no role in the incentive to collude in post-discovery periods.

However, a greater equilibrium industry profit after a discovery raises the expected profit before a discovery from $\left(v_{i}+v_{n}\right) / 2$ to $\underline{m} / 2$ in the expression $V_{c}$. That is, 
with licensing the collusive equilibrium profit before a discovery is equal to $\mathrm{V}_{\mathrm{J}}$ instead of $\mathrm{V}_{\mathrm{c}}$. On the other hand, the profit from a deviation before a discovery is unaffected by licensing and equals $V_{\lambda}$. Then, following the procedure of section 4 , we can show that collusion can be maintained in pre-discovery periods for $\delta \geq \max \left\{\delta^{\mathrm{A}}(\underline{\mathrm{c}}), 1 / 2\right\}=\delta^{\mathrm{A}}(\underline{\mathrm{c}})$. In terms of figure 1, licensing enables firms collude before and after a discovery in regions 1 and 2, while without licensing they could not collude before a discovery in region 2 , as shown in section 3.1. The analysis for regions 3 and 4 is unaffected by licensing.

Now reconsider formation of an RJV. Since licensing enables firms to collude before and after discovery in regions 1 and 2, formation of an RJV facilitates collusion only in regions 3 and 4 . Further, since firms share innovation with licensing and capture a greater industry profit after a discovery, an RJV does not generate additional efficiency gains, and hence does not increase welfare. In regions 3 and 4, an RJV facilitates collusion and reduces welfare. Without licensing an RJV increased welfare in region 1 due to the efficiency gain and the net effect was ambiguous in region 2. With licensing, however, an RJV causes no welfare changes in these regions.

In section 1 we indicated that an RJV can facilitate collusion by elimination of inter-firm asymmetries and generation of a greater industry profit. The analysis of this section can disentangle these two effects. First, both an RJV and licensing yields the identical expected collusive equilibrium profits before a discovery equal to $\mathrm{V}_{\mathrm{J}}$. Yet, due to the post-discovery asymmetry with licensing, firms cannot collude in regions 3 and 4 without forming an RJV. Thus, elimination of the post-discovery asymmetry is responsible for successful collusion in regions 3 and 4 with an RJV. Second, in region 2 
firms could not collude before a discovery without licensing but can collude with licensing or an RJV, both of which yields a greater surplus. Thus, collusion in region 2 is facilitated by the prospect of a greater profit with an RJV.

\section{Extensions}

In section we relax the following assumptions of the model. They are (i) nondrastic innovation, (ii) permanent patent protection, and (iii) Nash threats (punishment by reversions to repeated play of a one-shot game).

First, suppose innovation is drastic as in Martin (1995). With drastic innovation an innovator becomes a monopoly so there is no collusion in post-discovery periods. Thus, the analysis is similar to the one associated with region 3; namely, formation of an RJV facilitates collusion in post-discovery periods and lowers social welfare, which is exactly what Martin (1995) has argued.

Second, suppose that patent life is finite. If patent life is, say, T periods, the value of new technology to the innovator falls from $\pi_{L} /(1-\delta)$ under permanent patent protection to $\pi_{L}\left(1-\delta^{T}\right) /(1-\delta) .{ }^{20}$ In the collusive equilibrium finite patent life thus decreases the value of a deviation, thereby making collusion easier to maintain both before and after a discovery.

Third, it is well known in the implicit collusion literature that collusion can be sustained for a lower range of discount factors if firms can commit to a severer punishment scheme than Nash reversions. In a recent paper Thal (2006) considers such a 
scheme for Bertrand duopoly with asymmetric costs, and finds that a credible punishment strategy with an Abreu $(1986,1988)$ stick-and-carrot structure reduces the payoff to the firm with lowest cost to zero. Although not concerned with the uniqueness of equilibrium selection, when applied to our model, her analysis implies that there is an optimal punishment scheme that can reduce the threshold discount factor after a discovery to $1 / 2$ without formation of an RJV. However, it is not clear whether the threshold discount factor also falls to $1 / 2$ in pre-discovery periods. Nonetheless, in Appendix F we show that that is the case under the assumption of linear demand. In that case, firms can collude before and after a discovery at any discount factor greater or equal to $1 / 2$ without forming an RJV, meaning that cooperation in $R \& D$ always improves social welfare through efficiency gains.

\section{Concluding remarks}

We examine whether cooperation in R\&D leads to product market collusion. Our model has two firms managing implicitly to maintain the collusive equilibrium while engaged in a stochastic $R \& D$ race. Under competitive $R \& D$, innovation gives rise to an inter-firm cost asymmetry and can destabilizes collusion when the discount factor is low or the cost reduction under new technology is large. The prospect that collusion ends with innovation further destabilizes collusion in pre-discovery periods. Innovation sharing under cooperative $R \& D$ preserves a cost symmetry and also raises industry surplus, both of which facilitate collusion in product markets. These two effects can be studied

\footnotetext{
${ }^{20}$ In period $\mathrm{T}+1$ the technology becomes public and competition wipes out profits for the innovator.
} 
separately by considering the intermediate case, in which firms license without forming an RJV.

Although facilitating collusion, cooperation in R\&D does not necessarily decrease social welfare in the absence of licensing, as sharing of new technology improves efficiency in production. Although new technology is the driving force for a welfare improvement, cooperation in $\mathrm{R} \& \mathrm{D}$ is more likely to decrease welfare if the cost falls too much under new technology.

Our qualitative results are robust to alternative assumptions concerning the type of innovation (drastic or non-drastic), patent length, and punishment mechanisms. Our model can be extended further. For example, more complex licensing schemes such as multi-period binding licensing contracts can be explored within out model. Another interesting extension would be to the case of quantity-setting firms. Since quantity competition is less competitive it is generally more difficult to maintain collusion than with price competition. While we leave these extensions for future research, we believe that our basic insight and results will remain valid and relevant. 


\section{Appendices}

Appendix A: Proof of Lemma 1. Let $\delta<\delta^{\mathrm{A}}(\underline{\mathrm{c}})$ be given. Suppose there is a pair $\left(\mathrm{p}^{*}, \mathrm{~s}^{*}\right)$, where $\mathrm{p}^{*} \neq \mathrm{p}^{\mathrm{m}}(\underline{\mathrm{c}})$, such that $\mathrm{p}^{*}$ maximizes the innovator's profit $\mathrm{s}^{*} \underline{\mathrm{m}}^{*}=\mathrm{s}^{*} \mathrm{D}\left(\mathrm{p}^{*}\right)\left(\mathrm{p}^{*}-\underline{\mathrm{c}}\right)$ and satisfies the no-deviation constraints for both the innovator and the non-innovator.

Case $1 . \mathrm{p}^{*}<\mathrm{p}^{\mathrm{m}}(\underline{\mathrm{c}})$

Partial collusion is stable if

$$
\left.\delta \geq \max \left\{\left(1-\mathrm{s}^{*}\right) \underline{\mathrm{m}}^{*}\right) /\left(\underline{\mathrm{m}}^{*}-\pi_{\mathrm{L}}\right), \mathrm{s}^{*}\right\}
$$

If $\left.\delta \geq\left(1-\mathrm{s}^{*}\right) \underline{\mathrm{m}}^{*}\right) /\left(\underline{\mathrm{m}}^{*}-\pi_{\mathrm{L}}\right)>\mathrm{s}^{*}, \mathrm{~s}^{*}$ can be increased up to $\delta$, increasing the profit to the innovator without violating the no-deviation constraint. So, at the optimum the innovator sets $\mathrm{s}^{*}=\delta$. Therefore, we have

$$
\delta \geq(1-\delta) \underline{m} * /\left(\underline{m}^{*}-\pi_{L}\right)
$$

or

$$
\delta \geq \underline{m}^{*} /\left(2 \underline{m}^{*}-\pi_{L}\right)
$$

But the right-hand side is decreasing in $\mathrm{m}^{*}$ for $0 \leq \underline{\mathrm{m}} * \underline{\mathrm{m}}$, and hence

$$
\delta \geq \underline{m}^{*} /\left(2 \underline{m}^{*}-\pi_{L}\right)>\underline{m} /\left(2 \underline{m}-\pi_{L}\right)=\delta^{A}(\underline{c}),
$$

which contradicts the assumption $\delta<\delta^{\mathrm{A}}(\underline{\mathrm{c}})$.

Case: $\mathrm{p}^{\mathrm{m}}(\underline{\mathrm{c}})<\mathrm{p}^{*}<\mathrm{p}^{\mathrm{m}}(\overline{\mathrm{c}})$

There is no deviation if 


$$
\delta \geq \max \left\{\left(\underline{\mathrm{m}}-\mathrm{s}^{*} \underline{\mathrm{m}}^{*}\right) /\left(\underline{\mathrm{m}}-\pi_{\mathrm{L}}\right), \mathrm{s}^{*}\right\} .
$$

Again, $\mathrm{s}^{*}$ can be increased up to $\delta$ without violating this constraint so $\delta=\mathrm{s}^{*}$. We can write the above as

$$
\delta \geq(\underline{m}-\delta \underline{m} *) /\left(\underline{m}-\pi_{L}\right) .
$$

that is,

$$
\delta \geq \underline{\mathrm{m}} /\left(\underline{\mathrm{m}}-\pi_{\mathrm{L}}+\underline{\mathrm{m}}^{*}\right)
$$

But since $\underline{m}^{*}<\underline{m}$

$$
\delta \geq \underline{m} /\left(\underline{m}-\pi_{L}+\underline{m}^{*}\right)>\underline{m} /\left(2 \underline{m}-\pi_{L}\right)=\delta^{A}(\underline{c}),
$$

a contradiction.

Case 3: $\mathrm{p}^{*} \geq \mathrm{p}^{\mathrm{m}}(\overline{\mathrm{c}})$.

The innovator does not deviate if

$$
\delta \geq\left[\overline{\mathrm{m}}-\left(1-\mathrm{s}^{*}\right) \overline{\mathrm{m}} *\right] / \overline{\mathrm{m}},
$$

and the non-innovator does not if

$$
\delta \geq\left(\underline{m}-s^{*} \underline{m}^{*}\right) /\left(\underline{m}-\pi_{L}\right) .
$$

Partial collusion is sustained if both conditions hold. The first must hold with equality, for otherwise the innovator can increase profit by raising $\mathrm{s}^{*}$. Therefore, $\mathrm{s}^{*}$ satisfies

$$
(1-\delta) \bar{m}=\left(1-s^{*}\right) \bar{m}^{*}
$$

Using this the second condition can be written

$$
\delta\left(\underline{\mathrm{m}}-\pi_{\mathrm{L}}\right) \geq\left(\underline{\mathrm{m}}-\mathrm{s}^{*} \underline{\mathrm{m}}^{*}\right)=\underline{\mathrm{m}}+(1-\delta) \overline{\mathrm{m}}-\overline{\mathrm{m}}^{*}
$$


Collecting terms,

$$
\delta \geq\left[\underline{\mathrm{m}}+\overline{\mathrm{m}}-\overline{\mathrm{m}}^{*}\right] /\left[\left(\underline{\mathrm{m}}-\pi_{\mathrm{L}}+\overline{\mathrm{m}}\right]>\underline{\mathrm{m}} /\left(2 \underline{\mathrm{m}}-\pi_{\mathrm{L}}\right)=\delta^{\mathrm{A}}(\underline{\mathrm{c}}),\right.
$$

a contradiction.

Appendix B: We show that (6) fails at $\delta=1 / 2$. Assume the contrary, and evaluate (6) at $\delta$ $=1 / 2$ to obtain this equivalent condition:

$$
\underline{m}+D\left[p^{m}(\underline{c})\right]\left[p^{m}(\underline{c})-\bar{c}\right]-\pi_{L}-2 \bar{m} \geq 0 .
$$

However, we can express the left-hand side of (B1) as

$$
\begin{aligned}
& \mathrm{D}\left[\mathrm{p}^{\mathrm{m}}(\underline{\mathrm{c}})\right]\left[2 \mathrm{p}^{\mathrm{m}}(\underline{\mathrm{c}})-\overline{\mathrm{c}}-\underline{\mathrm{c}}\right]-\mathrm{D}(\overline{\mathrm{c}})(\overline{\mathrm{c}}-\underline{\mathrm{c}})-2 \mathrm{D}\left[\mathrm{p}^{\mathrm{m}}(\overline{\mathrm{c}})\right]\left[\mathrm{p}^{\mathrm{m}}(\overline{\mathrm{c}})-\overline{\mathrm{c}}\right) \\
& <2 \mathrm{D}(\overline{\mathrm{c}})\left[\mathrm{p}^{\mathrm{m}}(\underline{\mathrm{c}})-\overline{\mathrm{c}}\right]-2 \mathrm{D}\left[\mathrm{p}^{\mathrm{m}}(\overline{\mathrm{c}})\right]\left[\mathrm{p}^{\mathrm{m}}(\overline{\mathrm{c}})-\overline{\mathrm{c}}\right) \\
& <0
\end{aligned}
$$

where the first inequality is obtained from substitution of $\mathrm{D}(\overline{\mathrm{c}})$ for $\mathrm{D}\left[\mathrm{p}^{\mathrm{m}}(\underline{\mathrm{c}})\right]$ while the second follows the fact that $\mathrm{p}^{\mathrm{m}}(\overline{\mathrm{c}})$ is the profit-maximizing price at cost $\overline{\mathrm{c}}$. This contradiction is what we wanted.

Appendix C: We prove Lemma 2. Proof of Result (i) $d \delta^{\mathrm{B}}(\underline{\mathrm{c}}) / \mathrm{d} \underline{\mathrm{c}}<0$. Write $\delta^{\mathrm{B}}(\underline{\mathrm{c}})=\delta^{\mathrm{B}}$ to save space. $\delta^{\mathrm{B}}$ is implicitly defined by (6) or satisfies this implicit function

$$
\mathrm{g}\left(\delta^{\mathrm{B}}, \underline{\mathrm{c}}\right) \equiv \mathrm{V}_{\mathrm{J}}-\mathrm{V}_{\lambda}-\overline{\mathrm{m}}=0 .
$$


where $V_{J}-V_{\lambda}$ is given by $(7)$. Write $g\left(\delta^{B}, \underline{c}\right)=g$. Straightforward differentiation of (7) shows that $\partial \mathrm{g} / \partial \delta^{\mathrm{B}}>0$. On the other hand,

$$
\operatorname{sgn}\{\partial \mathrm{g} / \partial \underline{\mathrm{c}}\}=\operatorname{sgn}\left\{\partial\left(\mathrm{V}_{\mathrm{J}}-\mathrm{V}_{\lambda}\right) / \partial \underline{\mathrm{c}}\right\}=\operatorname{sgn}\left\{\partial\left(\pi_{\mathrm{i}}+\pi_{\mathrm{n}}-\pi_{\mathrm{L}}\right) / \partial \underline{\mathrm{c}}\right\}
$$

The last derivative is

$$
-\delta^{\mathrm{B}} \mathrm{D}\left[\mathrm{p}^{\mathrm{m}}(\underline{\mathrm{c}})\right]+\mathrm{D}(\overline{\mathrm{c}})>0
$$

since $\mathrm{p}^{\mathrm{m}}(\underline{\mathrm{c}})>\overline{\mathrm{c}}$. Therefore, by the implicit-function theorem we conclude that

$$
\mathrm{d} \delta^{\mathrm{B}}(\underline{\mathrm{c}}) / \mathrm{d} \underline{\mathrm{c}}=-(\partial \mathrm{g} / \partial \underline{\mathrm{c}}) /\left(\partial \mathrm{g} / \partial \delta^{\mathrm{B}}\right)<0 .
$$

Proof of Result (ii): As $\underline{c}$ approaches $c^{d}, V_{c}-V_{\lambda}$ approaches $(\bar{m} / 2)\left(1-\delta \phi^{2}\right)$. Therefore, if $\delta>1 /\left(2 \phi^{2}\right)$, (6) holds with strict inequality at the limit $\underline{c}=c^{d}$, that is,

$$
(\overline{\mathrm{m}} / 2) /\left(1-\delta \phi^{2}\right)>\overline{\mathrm{m}}
$$

This implies that $\delta^{\mathrm{B}}(\underline{\mathrm{c}})$ is bounded from above by $1 /\left(2 \phi^{2}\right)$.

Proof of Result (iii). Suppose that $\phi^{2} \geq 1 / 2$. Then $1 /\left(2 \phi^{2}\right) \leq 1$. Hence, $1>\delta^{\mathrm{B}}(\underline{\mathrm{c}})>1 / 2$ by result (ii) of lemma 2 . On the other hand, $\delta^{\mathrm{A}}(\underline{\mathrm{c}})$ approaches unity as $\underline{\mathrm{c}}$ approaches $\mathrm{c}^{\mathrm{d}}$, and approaches $1 / 2$ as $\underline{\mathrm{c}}$ nears $\overline{\mathrm{c}}$. Thus, the two loci cross each other.

Appendix D. We prove Lemma 3: Let $\delta$ be given such that $\delta^{\mathrm{A}}(\underline{\mathrm{c}}) \leq \delta<\delta^{\mathrm{B}}(\underline{\mathrm{c}})$. Suppose there is a price $\mathrm{p}^{*} \neq \mathrm{p}^{\mathrm{m}}(\overline{\mathrm{c}})$ and the total profit $\overline{\mathrm{m}}^{*}=\mathrm{D}\left(\mathrm{p}^{*}\right)\left(\mathrm{p}^{*}-\overline{\mathrm{c}}\right)<\overline{\mathrm{m}}$ satisfying 


$$
\frac{\delta\left(1-\phi^{2}\right)\left[v_{i}+v_{n}-\pi_{L} /(1-\delta)\right] / 2+\bar{m}^{* / 2}}{1-\delta \phi^{2}} \geq \bar{m}^{*}
$$

But firms cannot collude fully so

$$
\overline{\mathrm{m}}>\frac{\delta\left(1-\phi^{2}\right)\left[\mathrm{v}_{\mathrm{i}}+\mathrm{v}_{\mathrm{n}}-\pi_{\mathrm{L}} /(1-\delta)\right] / 2+\overline{\mathrm{m}} / 2}{1-\delta \phi^{2}}
$$

Adding and simplifying

$$
\left[\overline{\mathrm{m}}-\overline{\mathrm{m}}^{*}\right] /\left[2\left(1-\delta \phi^{2}\right)\right] \geq \overline{\mathrm{m}}-\overline{\mathrm{m}}^{*}
$$

which holds only if

$$
\delta>1 /\left(2 \phi^{2}\right) .
$$

By Lemma 2,

$$
1 /\left(2 \phi^{2}\right)>\delta^{\mathrm{B}}(\underline{\mathrm{c}}) .
$$

These two imply $\delta>\delta^{\mathrm{B}}(\underline{\mathrm{c}})$, a contradiction.

Appendix E: We show that (8) holds with strict inequality at $\delta=1 / 2$. First we show:

$$
\begin{aligned}
& \underline{\mathrm{m}}-\pi^{\mathrm{L}}-\overline{\mathrm{m}} \\
& =\mathrm{D}\left[\mathrm{p}^{\mathrm{m}}(\underline{\mathrm{c}})\right]\left[\mathrm{p}^{\mathrm{m}}(\underline{\mathrm{c}})-\underline{\mathrm{c}}\right]-\mathrm{D}(\overline{\mathrm{c}})(\overline{\mathrm{c}}-\underline{\mathrm{c}})-\mathrm{D}\left[\mathrm{p}^{\mathrm{m}}(\overline{\mathrm{c}})\right]\left[\mathrm{p}^{\mathrm{m}}(\overline{\mathrm{c}})-\overline{\mathrm{c}}\right) \\
& >\mathrm{D}\left[\mathrm{p}^{\mathrm{m}}(\underline{\mathrm{c}})\right]\left[\mathrm{p}^{\mathrm{m}}(\underline{\mathrm{c}})-\underline{\mathrm{c}}\right]-\mathrm{D}(\overline{\mathrm{c}})(\overline{\mathrm{c}}-\underline{\mathrm{c}})-\mathrm{D}(\overline{\mathrm{c}})\left[\mathrm{p}^{\mathrm{m}}(\overline{\mathrm{c}})-\overline{\mathrm{c}}\right) \\
& =\mathrm{D}\left[\mathrm{p}^{\mathrm{m}}(\underline{\mathrm{c}})\right]\left[\mathrm{p}^{\mathrm{m}}(\underline{\mathrm{c}})-\underline{\mathrm{c}}\right]-\mathrm{D}(\overline{\mathrm{c}})\left[\mathrm{p}^{\mathrm{m}}(\overline{\mathrm{c}})-\underline{\mathrm{c}}\right)>0 .
\end{aligned}
$$

Second, evaluate $\mathrm{V}_{\mathrm{J}}-\mathrm{V}_{\lambda}$ at $\delta=1 / 2$ to obtain 


$$
\mathrm{V}_{\mathrm{J}}-\mathrm{V}_{\lambda}=\frac{\left(1-\phi^{2}\right)\left(\underline{\mathrm{m}}-\pi_{\mathrm{L}}\right)+\overline{\mathrm{m}}}{2-\phi^{2}}
$$

Subtract $\overline{\mathrm{m}}$ from it.

$$
\mathrm{V}_{\mathrm{J}}-\mathrm{V}_{\lambda}-\overline{\mathrm{m}}=\left(1-\phi^{2}\right)\left(\underline{\mathrm{m}}-\pi^{\mathrm{L}}-\overline{\mathrm{m}}\right) /\left(2-\phi^{2}\right)>0
$$

by (E1). Finally, evaluate the left-hand side of ( 8 ) at $\delta=1 / 2$ to obtain

$$
\begin{aligned}
& \left(1-\phi^{2}\right) \underline{\mathrm{m}} / 2+\phi^{2}\left(\mathrm{~V}_{\mathrm{J}}-\mathrm{V}_{\lambda}\right) / 2 \\
& >\left(1-\phi^{2}\right) \underline{\mathrm{m}} / 2+\phi^{2} \overline{\mathrm{m}} / 2 \\
& >\overline{\mathrm{m}} / 2
\end{aligned}
$$

where the first inequality uses (E2). But (E3) shows that (8) holds with strict inequality at $\delta=1 / 2$

Appendix F: Since he receives zero profits following a deviation, the innovator has no incentive to deviate if $\mathrm{s} \overline{\mathrm{m}} /(1-\delta) \geq \overline{\mathrm{m}}$, or $\mathrm{s} \geq 1-\delta$. Likewise, the non-innovator does not deviate if $\mathrm{s} \leq \delta$. Thus, $1-\delta \leq \mathrm{s} \leq \delta$. At $\delta=1 / 2$, this means $\mathrm{s}=1 / 2$. Now, modify the prediscovery components of $\mathbf{b}$ as follows. In state (iv) firms set price equal to $\overline{\mathbf{c}}$ until a discovery, after which they switch to the stick-and-carrot strategy described by Thal (2006). Then, a one-period deviation before a discovery yields zero profits (excluding k) past the period in which a deviation occurs, regardless of histories. It follows that a 
deviant firm chooses not to invest in R\&D investment. With this modification, (6) becomes

$$
\mathrm{V}_{\mathrm{c}} \geq \overline{\mathrm{m}} \text {. }
$$

Substituting $\delta=1 / 2$ and canceling terms, we can write this condition as

$$
\underline{\mathrm{m}}+\mathrm{D}\left[\mathrm{p}^{\mathrm{m}}(\underline{\mathrm{c}})\right]\left[\mathrm{p}^{\mathrm{m}}(\underline{\mathrm{c}})-\overline{\mathrm{c}}\right]-2 \overline{\mathrm{m}} \geq 0 .
$$

This condition may or may not hold in general but it does hold under the assumption of linear demand as can easily be confirmed by directly evaluation of the profits. If it does, then firms can maintain collusion before and after innovation at any $\delta \geq 1 / 2$ as under cooperative R\&D. $\square$ 


\section{References}

Abreu, D., 1986, Extremal equilibria of oligopolistic supergames, Journal of Economic Theory 39, 191-225.

Abreu, D., 1988, Towards a theory of discounted repeated game, Econometrica 56, 383396

Bae, Y., 1987, A price-setting supergame between heterogeneous firms, European Economic Review 31, 1159-1171

Bloch, F., and Markowitz, P, 1996, Optimal disclosure delay in multistage R\&D competition, International Journal of Industrial Organization 14, 159-179

Cabral, L. M. B., 2000, R\&D cooperation and product market competition, International Journal of Industrial Organization 18, 1033-1047

Caloghirou, Y., S. Ioannides, and N.S. Vonortas, 2003, Research joint ventures, Journal of Economic Surveys 17, 541-570

Cardon, J. H. and Sasaki, D., 1998, Preemptive search and R\&D clustering, RAND Journal of Economics 29, 324-338

Collie, D.R., 2004, Sustaining collusion with asymmetric costs, unpublished paper.

D'Aspremont, C, and Jacquemin, A., 1988, Cooperative and noncooperative R\&D in duopoly with spillovers, American Economic Review 78, 1133-1137.

Friedman, J.W., 1971, A non-cooperative equilibrium for supergames, Review of Economic Studies 38, 1 - 12.

Harrington, Jr., J. E., 1991, The determination of price and output quotas in a heterogeneous cartel, International Economic Review 32, 767-792 
Kamien, M. I., E. Muller, and I. Zang, 1992, Research joint ventures, and R\&D cartels, American Economic Review 82, 1293-1306.

Lambertini, L., S. Poddar and D. Sasaki, 2002, Research joint ventures, product differentiation, and price collusion, International Journal of Industrial Organization 20, 829-854

Lambertini, L., S. Poddar and D. Sasaki, 2003, RJVs in product innovation and cartel stability, Review of Economic Design 7, 465-477.

Martin, S., 1995, R\&D joint ventures and tacit product market collusion, European Journal of Political Economy 11, 733-741

Miyagiwa, K., and Y. Ohno, 2002, Uncertainty, spillovers, and cooperative R\&D, International Journal of Industrial Organization, 855-876

Rothschild, R., 1999, Cartel stability when costs are heterogeneous, International Journal of Industrial Organization 17, 717-734

Thal, J., Optimal collusion under cost asymmetry, unpublished paper

Verboven, F., 1997, Collusive behavior with heterogeneous firms, Journal of Economic Behavior and Organization 33, 121-136 


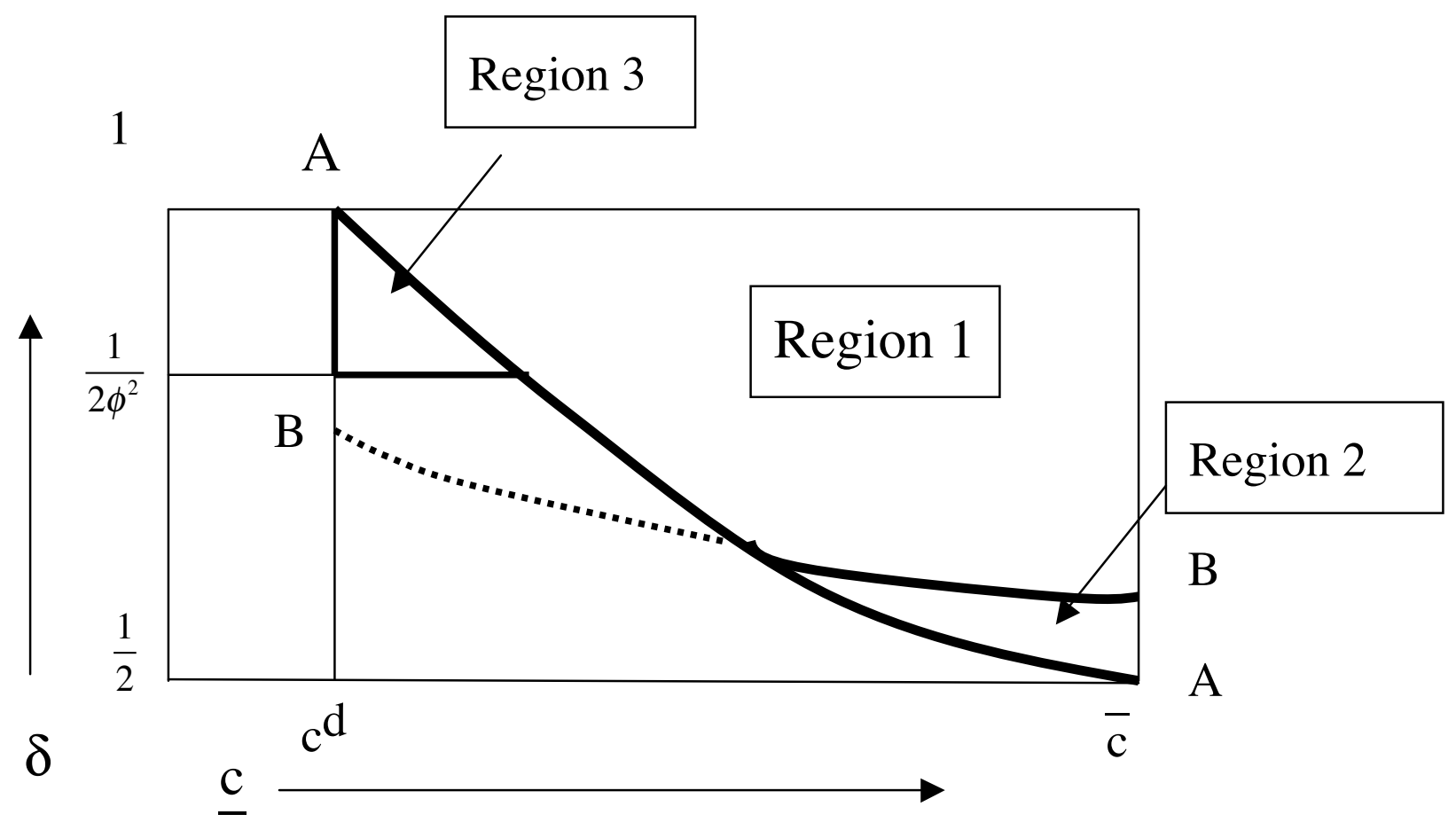

Figure 1 